\title{
Effect of Fiber Orientation on the Flexural Properties of PALF Reinforced Bisphenol Composites
}

\author{
Vinod B \\ Vidyavardhaka College of Engg \\ Mysore, India.
}

\author{
Sudev L J \\ Vidyavardhaka College of Engg \\ Mysore, India.
}

\begin{abstract}
Mankind has been aware of composite materials since several hundred years before Christ and applied innovation to improve the quality of life. Although it is not clear has to how man understood the fact that mud bricks made sturdier houses if lined with straw, he used them to make buildings that lasted. In recent years natural fibers appear to be the outstanding materials which are abundant and come as viable substitute for the expensive and nonrenewable synthetic fiber. Natural fibers like sisal, banana, jute, oil palm, kenaf and coir has been used as reinforcement in thermoset composite for applications in consumer goods, furniture, low cost housing and civil structures. Pineapple leaf fiber (PALF) is one of them that have also good potential as reinforcement in thermoset composite. The objective of the present work is to explore the potential of using PALF as reinforcement and investigate the effect of fiber orientation on the flexural properties of PALF reinforced Bisphenol composite. From this experimental study, it was observed that the fiber orientation greatly influences the flexural properties of reinforced composites. A higher flexural strength of $105.5754 \mathrm{Mpa}$ was obtained for inclined orientated fibers compared to that of Uni-directional \& Bi-directional oriented fibers.
\end{abstract}

Keywords: Pineapple leaf fiber, Bisphenol, anaerobic extraction, mechanical properties, flexural strength.

\section{INTRODUCTION}

Recently, composite materials have successfully substituted the traditional materials in several light weight and high strength applications. The reasons why composites are selected for such applications are mainly their high strengthto-weight ratio, high tensile strength at elevated temperatures, high creep resistance and high toughness. By definition, composites are materials consisting of two or more chemically distinct constituents on a macro scale having a distinct interface separating them and having bulk behavior which is considerably different from those of any of the constituents[1].

Two types of fibers can be used for reinforcing in the composite materials:

\section{Synthetic Fibers}

2. Natural Fibers

Synthetic fibers are the most widely used to reinforce plastics due to their low cost and fairly good mechanical properties. However, these fibers have serious drawbacks as high density, non-renewability, non-biodegradability, high energy consumption etc.

Growing environmental awareness and societal concern, a high rate of depletion of petroleum resources, the concept of sustainability, and new environmental regulations have triggered the search for new products that are compatible with the environment. Sustainability, 'cradle to grave' design, industrial ecology, eco-friendly and bio-compatibility are the guiding principles of development of new generation materials. Lignocellulosic reinforced composites are the materials of the new paradigm. The use of biodegradable and environment friendly plant-based fibers in the composites reduces waste disposal problems, environment pollution and ecological concerns.

India, endowed with an abundant availability of natural fibers such as jute, coir, sisal, pineapple, ramie, bamboo, banana etc., has focused on the development of natural fiber composites primarily to explore value-added application avenues. Due to an occurrence of a wide variety of natural fibers in the country, Indian researchers have directed efforts for quite some time in developing innovative natural fiber composites for various applications. While the national research agencies in India have excellent scientific achievements to their credit for development of natural fiber composites, efforts on their commercialization have been limited so far. The natural fiber composites can be very costeffective material especially for building \& construction industry (panels, false ceilings, partition boards etc.), packaging, automobile \& railway coach interiors and storage devices[2].

One such fiber source known for a long time is pineapple leaves from which pineapple leaf fibers (PALF) may be extracted. Pineapple (Ananas comosus) is the third most important tropical fruit in the world after banana and citrus. S.M.Sapuan et.al [3] reviewed the importance of pineapple leaf fiber by stating that PALF is the least studied natural fiber, especially for reinforcing composites. The article presented a survey of research works carried out on PALF and PALF-reinforced composites. Noor Sabah Sadeq [4] made experimental studies on Influence of Natural Fiber on the Mechanical Properties of Epoxy Composites. The study deals with the effects of natural fibers on some mechanical properties of the Epoxy composite. Jayamol George [5] made experimental studies on Short PineappleLeaf-Fiber-Reinforced Low-Density Polyethylene Composites. The influence of fiber length, fiber loading, and orientation on the mechanical properties has also been evaluated.

The objective of the present work is to investigate the effect of fiber orientation on flexural strength of the PALF reinforced polymer composite.

\section{MATERIALS AND METHODOLOGY}

PALF is one such fiber source known from a long time obtained from the leaves of pineapple plant (Ananascomosus) from the family of Bromeliaceae. The Food and Agriculture Organization (FAO) has reported that most of the world pineapple fruit production in 2001 amounting to about 13.7 million tons of fresh fruits are produced in Asia [6]. Pineapple leaves from the plantations are being wasted as they are cut after the fruits are harvested before being either composted or burnt. Additionally, burning of these beneficial agricultural wastes causes environmental pollution. Table 2.1 
shows some of the physical and mechanical properties of pineapple leaf fiber.

Table 2.1 Properties of pineapple leaf fiber:

\begin{tabular}{|c|c|}
\hline Property & Value \\
\hline Density $(\mathrm{g} / \mathrm{cm} 3)$ & 1.526 \\
\hline Softening Point $\left({ }^{\circ} \mathrm{C}\right)$ & 104 \\
\hline Tensile Strength $(\mathrm{MPa})$ & 170 \\
\hline Young's Modulus $(\mathrm{MPa})$ & 6260 \\
\hline Specific Modulus $(\mathrm{MPa})$ & 4070 \\
\hline Elongation at Break $(\%)$ & 3 \\
\hline Moisture regain $(\%)$ & 12 \\
\hline
\end{tabular}

Bisphenol-A (BPA) is an organic compound which belongs to the group of diphenyl methane derivatives and Bisphenol. The chemical formula is $\left(\mathrm{CH}_{3}\right)_{2} \mathrm{C}\left(\mathrm{C}_{6} \mathrm{H}_{4} \mathrm{OH}\right)_{2}$. BPA is used to make certain plastics and epoxy resins; it has been in commercial use since 1957. Table 2.2 shows some of the properties of Bisphenol resin.

Table 2.2 Properties of Bisphenol resin:

\begin{tabular}{|l|l|}
\hline Tensile strength & $30 \mathrm{Mpa}$ \\
\hline Tensile modulus & $3300 \mathrm{Mpa}$ \\
\hline Elongation at break & $2 \%$ \\
\hline Flexure strength & $80 \mathrm{Mpa}$ \\
\hline Flexure modulus & $3100 \mathrm{Mpa}$ \\
\hline Melting point & $156-159^{0} \mathrm{C}$ \\
\hline Specific gravity & $1.19-1.20$ \\
\hline Impact strength & $2.0-2.2 \mathrm{~kJ} / \mathrm{m}^{2}$ \\
\hline Poisson's ratio & 0.37 \\
\hline
\end{tabular}

\subsection{Extraction of fibers}

PALF were extracted from the leaf of pineapple plant by biological method. The conventional extraction processes like retting leads to serious problems like methane and sulphide emission, water contamination and other environmental pollutions. Owing to the above factors, biological method is preferred to mechanical and chemical routes for extracting fibers of good quality from embedding matrix. It is in this context that National Institute of Interdisciplinary Science and Technology (NIIST), Trivandrum, Kerala devised a clean anaerobic process to yield superior quality fibers while shortening the processing time substantially. Here separation of fibers from their matrices is achieved by enzymatic cleaving of cementing compounds with in situ microbial growth and enzyme production. The organic residue generated by the process is converted to methane that can be recovered for fuel.

\subsection{Chemical treatment}

Alkali treatment or mercerization using sodium hydroxide $(\mathrm{NaOH})$ is the most commonly used treatment for bleaching and cleaning the surface of natural fibers to produce high-quality fibers. Modifying natural fibers with alkali has greatly improved the mechanical properties of the resultant composites.
The following steps were carried out during chemical treatment:

- $5 \% \mathrm{NaOH}$ solution was prepared using sodium hydroxide pellets and distilled water.

- Pineapple leaf fibers were then dipped in the solution for 1 hour.

- After 1 hour fibers were washed with $1 \% \mathrm{HCl}$ solution to neutralize the fibers.

- Then it is washed with distilled water.

- It was then kept in hot air oven for 3hours at 65 $70^{\circ} \mathrm{C}$.

\subsection{Manufacturing of composite}

A polypropylene (PP) mould having dimensions of $150 \times 100 \times 4 \mathrm{~mm}$ is used for composite fabrication. The mould was first cleaned with wax so that the laminate easily comes out of the die after hardening. Then around 15 to $20 \mathrm{ml}$ of promoter and accelerator are added to Bisphenol and the color of the resin changes from pale yellow to dark yellow with the addition of these two agents. The laminates of three different fibers orientations mats of unidirectional, bidirectional and inclined are prepared using hand layup method. This method of manufacturing is a relatively simple method compared to other methods like vacuum bag molding, resin transfer molding, autoclave molding etc. Figure 2.1, 2.2 and 2.3 shows the uni-directional, bi-directional and inclined orinted PALF reinforced composites respectively.

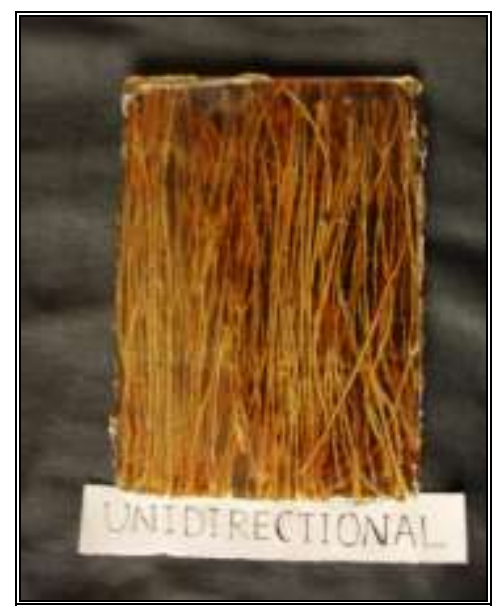

Figure 2.1 Uni-directional oriented PALF reinforced composites

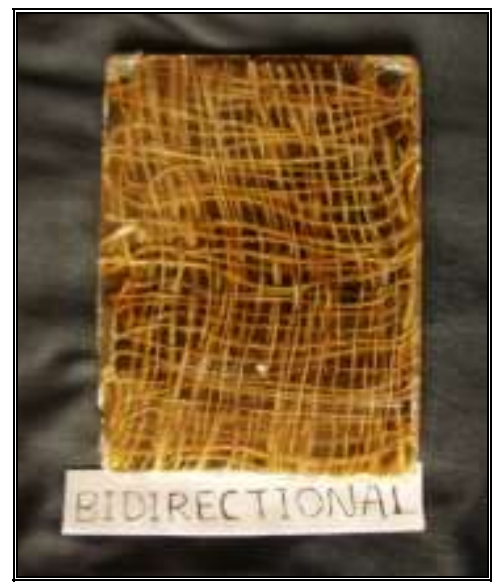

Figure 2.2. Bi-directional oriented PALF reinforced composites 


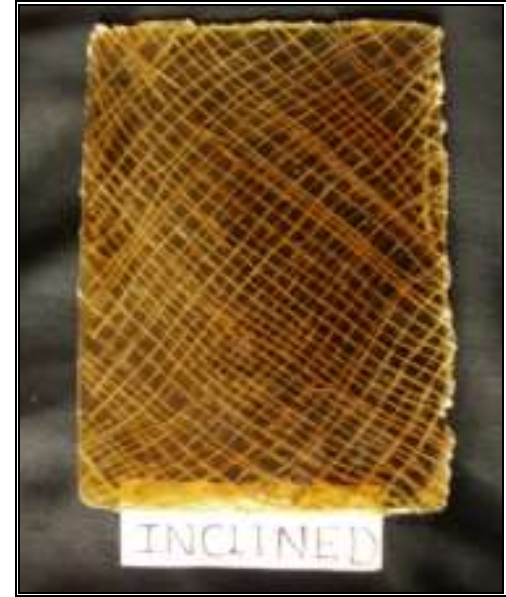

Figure 2.3. Inclined oriented PALF reinforced composites

\section{RESULTS AND DISCUSSION}

The flexural properties of the unidirectional, bidirectional and inclined PALF reinforced composites was studied. There are two methods to determine the flexural properties of material: three-point loading system and four point loading system. In the present work three-point loading bending test was carried out on a test specimen as per ASTM D790 standard $(125 * 14.5 * 4 \mathrm{~mm})$. The flexural test was conducted on JJ Lloyd universal testing machine with load cell of $1 \mathrm{kN}$ and using crosshead speed of $5 \mathrm{~mm} / \mathrm{min}$. The test was performed until the flexural failure occurred. Fig. 3.1 shows three-point bending test.

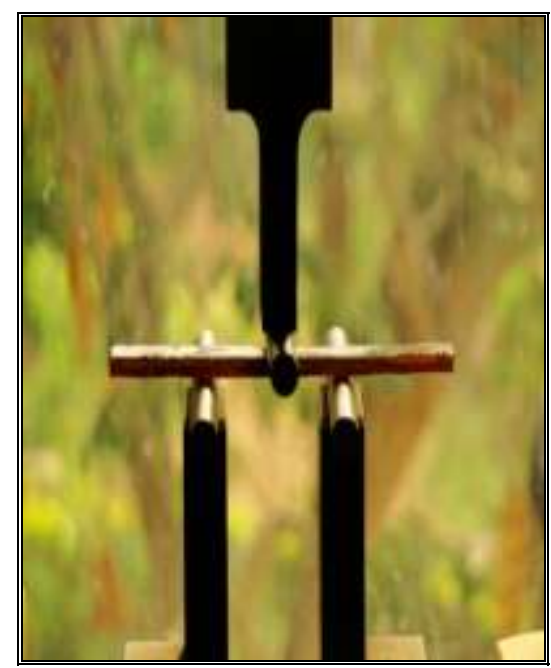

Figure 3.1-Test Specimen undergoing flexural test

The results of the flexural test are put forth in the form of stress-strain curves. Figures 3.2(a), 3.2(b) and 3.2(c) shows the stress-strain curve for unidirectional, bidirectional and inclined PALF composite respectively. The maximum load and maximum bending stress obtained from the experimental study is given in Table 3.2. Figure 3.3 shows the variation of maximum bending stress for different orientation of fibers in the composite.

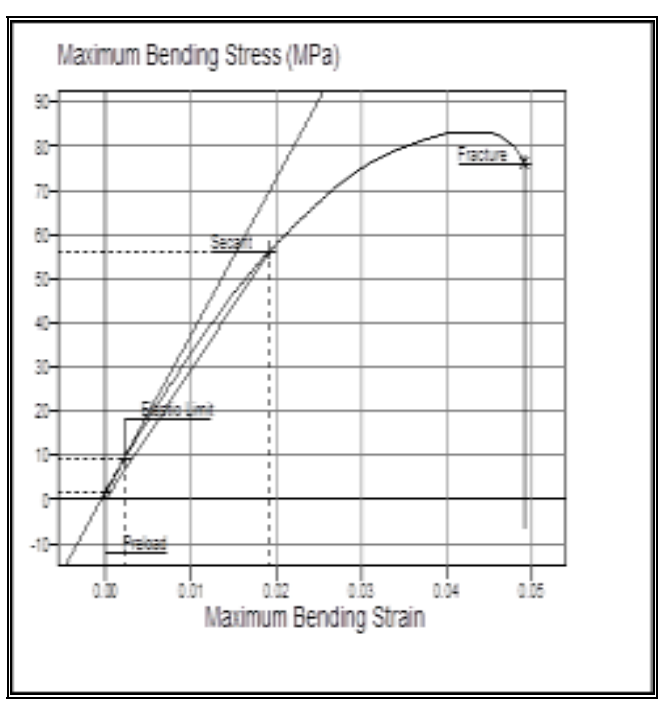

Figure 3.2(a) - Stress-strain curve of Uni- directional composite.

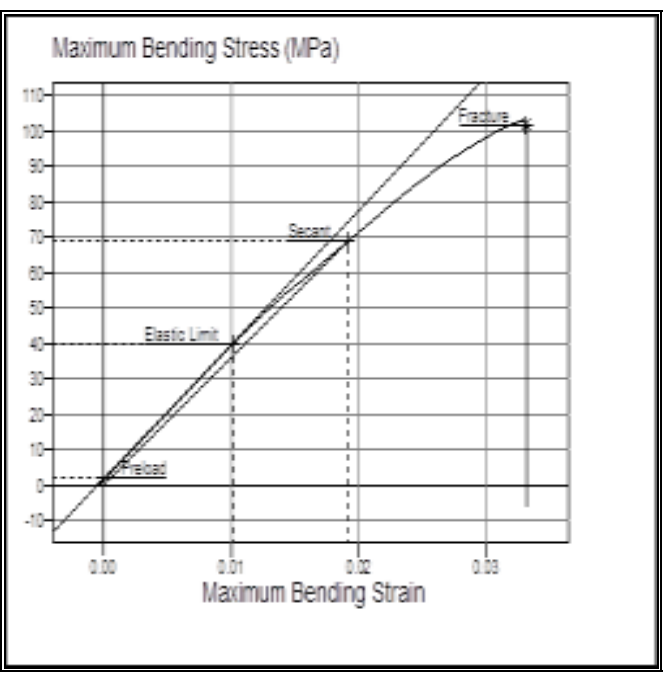

Figure 3.2(b) - stress strain curve if $\mathrm{Bi}$ - direction composite.

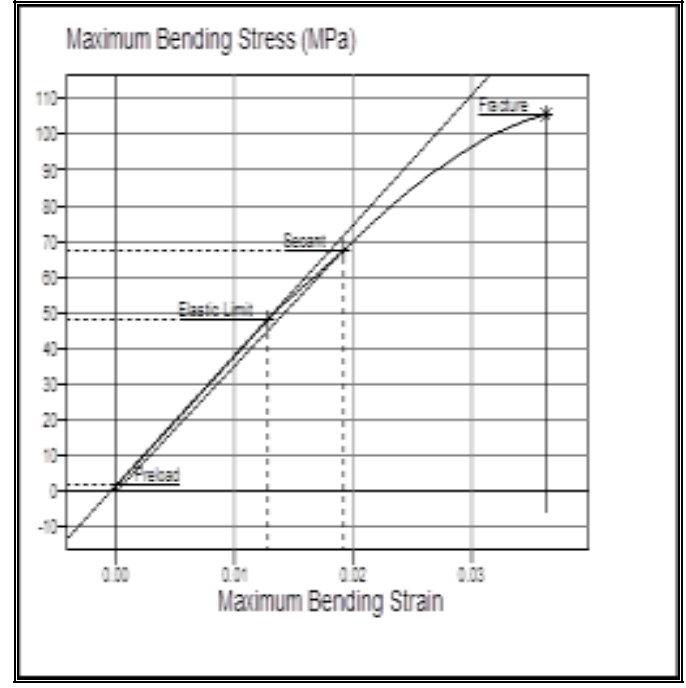

Figure 3.2(c) - Stress strain curve of inclined PALF composite. 
Table 3.1 shows the maximum load and maximum binding stress for Uni-directional, Bi-directional and inclined fiber oriented reinforced polymer composite.

Table 3.1 Experimantal results:

\begin{tabular}{|c|c|c|}
\hline $\begin{array}{c}\text { Fiber } \\
\text { Orientation }\end{array}$ & $\begin{array}{c}\text { Maximum } \\
\text { load(KN) }\end{array}$ & $\begin{array}{c}\text { Maximum bending stress } \\
(\mathrm{MPa})\end{array}$ \\
\hline Uni-directional & $\mathbf{0 . 2 2 6 5 1 4 9 9 8}$ & $\mathbf{8 3 . 6 0 5 4 3 7 2 3}$ \\
\hline Bi-directional & $\mathbf{0 . 2 7 8 6 7 8 0 7 6}$ & 102.8585419 \\
\hline Inclined & $\mathbf{0 . 2 8 6 0 3 9 1 6 3}$ & 105.5754786 \\
\hline
\end{tabular}

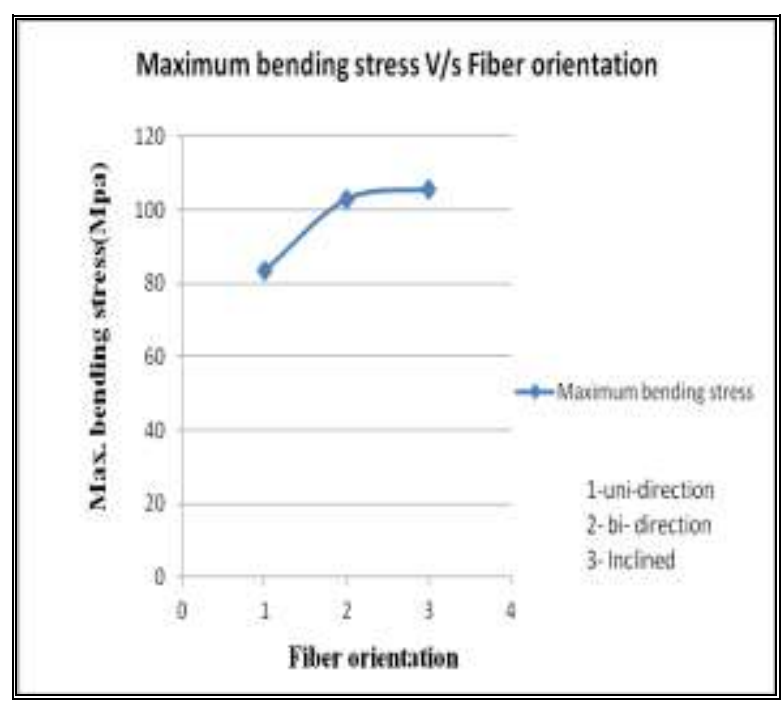

Figure 3.3 Variation of Maximum bending stress with fiber orientation.

The flexural strength of the matrix material Bisphenol alone is $80 \mathrm{Mpa}$ (Table 2.2). From the table 3.1 it can be observed that the highest value of flexural strength of $105.57 \mathrm{Mpa}$ is obtained for inclined orientated fibers. In comparison with the flexural strength of matrix material, the reinforcement of fibres in inclined direction $\left(45^{\circ}\right)$ increased the flexural strength of the composite by $24.22 \%$. For Uni-directionally orientated fibers maximum bending stress marginally increased by $4.3 \%$ and for bi-directional orientated fibers it increased to $22.21 \%$ than the matrix material's value.

\section{CONCLUSION}

The results of the present study revealed that a useful composite with good properties could be successfully developed using treated PALF as reinforcing agent for the Bisphenol matrix. It can be seen that inclined oriented composites show better flexural strength (105.57 MPa) than Uni-directional and bi-directional oriented composites. Hence fiber orientation greatly influence the flexural strength of the PALF reinforced Bisphenol composite.

\section{REFERENCES}

[1] D. W. Clegg and A. A. Collyer, Mechanical Properties of reinforced thermoplastics, Elsevier Applied Science Publishers, London and New York, 1986.
[2] P. K. Mallick, Fibre Reinforced Composites, Marcel Dekker. Inc., New York, 1988.

[3] Arib, R.M.N., Sapuan, S.M., Hamdan, M.A.M.M., Paridah, M.T. and Zaman, H.M.D.K. (2004). A Literature Review of Pineapple Fiber Reinforced Polymer Composites. Polymer and Polymer Composites. 12(4): 341-348.

[4] Noor Sabah Sadeq. Influence of Natural Fiber on the Mechanical Properties of Epoxy Composites. Eng. \& Tech. Journal, Vol.28, No.17, 2010.

[5] Sabu Thomas. Short Pineapple-Leaf-Fiber-Reinforced Low-Density Polyethylene Composites. Journal of Applied Polymer Science. vol. 57. 841-864 11996).

[6] Drzal, L.T., Mohanty, A.K., Burgueño, R. and Misra, M. (2003). Biobased Structural Composite Materials for Housing and Infrastructure Applications: Opportunities and Challenges. Composite Science and Technology. 63: 129-140.

[7] Ramakrishna Malkapuram, Vivek Kumar, and Yuvraj Singh NegiRecent Development in Natural Fiber Reinforced Polypropylene Composites Journal of Reinforced Plastics and Composites 2009 28:11691189:10.1177/0731684407087759

[8] Munirahmokhtar, Abdul Rrazakrahmat, Azman Hassan (2007) Characterization and treatments of pineapple leaf fiber thermoplastic composite for construction applications volume 75147

[9] Uma Devi, L., Bhagawan, S.S. and Thomas, S. (1997). Mechanical Properties of Pineapple Leaf FiberReinforced Polyester Composites. Journal of Applied Polymer Science. 64: 1739-1748.

[10] Arib, R.M.N. (2003). Mechanical Properties of Pineapple Leaf Fiber Reinforced Polypropylene Laminated Composites. University Putra Malaysia. Master's Thesis.

[11] American Standard of Testing and Materials-ASTM International (2003). Standard Test Method for Tensile Properties of Plastics. United State, ASTM 638-03.

[12] American Standard of Testing and Materials-ASTM International (2003). Standard Test Methods for Flexural Properties of Unreinforced and Reinforced Plasticsand Electrical Insulating Materials. United State, ASTM D790-03 